\title{
Phenotyping, endotyping and clinical decision-making
}

We have exiting times in the treatment of chronic rhinosinusitis (CRS). The last year has brought us a number of new ideas and publications to help in decision-making in daily practice. In the first issue of this year, Claire Hopkins and co-authors identified the most important outcomes for patients, public and practitioners that should be evaluated in studies on health interventions for CRS (1). In this issue of the journal, a group of experts tried to define appropriateness criteria for endoscopic sinus surgery during management of uncomplicated adult chronic rhinosinusitis. Appropriate indications for endoscopic sinus surgery (ESS) are currently poorly defined and the lack of clear surgical indications for ESS likely contributes to the large geographic variation in surgical rates. Using the Delphi method a total of 624 clinical scenarios (half CRSsNP and half CRSwNP) were ranked. The study clearly states that this group of experts indicates that ESS can only be indicated after medical treatment has failed with patients still having significant symptoms (SNOT-22 $\geq 20$ ) and at least some abnormalities at CT scan ${ }^{(2)}$. Although it certainly does not mean that all patients fulfilling these minimal criteria should be operated, I hope that it prevents patients to be operated that do not fulfill these criteria. Although we know quite well which patients within reason will not benefit from surgery, it is much more difficult to advise patients when surgery will help them. The studies published last year by Hopkins et al. showing that patients with CRS do better when operated early in their disease and that early surgery might prevent the development of asthma even further complicated the decision $(3,4)$. Now not only the present symptoms but potentially also future effects have to be taken into account. These data coming from the National Comparative Audit of Surgery for Nasal Polyposis and Chronic Rhinosinusitis need to be substantiated in prospective trials with standardized questionnaires but for the moment they let you wonder whether it is better to operate earlier. Even more than for first surgery we wonder when to perform revision surgery. In this issue of the Journal, Rudmik et al. show that failing to achieve an improvement of greater than one minimal clinically important difference (MCID, 9 points in the SNOT_22) at 3 months after primary ESS and a deterioration of greater than one MCID) from the 3- to 12-month follow-up period was associated with an increased risk of revision ESS ${ }^{(5)}$. Of course rather than doing revision surgery we would like to have other, better treatment options for our patients. We know that postoperative corticosteroids can improve recurrence rates in cases of CRSwNP (6) but now new options of precision medicine ${ }^{(7,8)}$ with endotyping patients ${ }^{\left({ }^{9}\right)}$ and precise treatments with monoclonal antibodies come into reach ${ }^{(10-12)}$. In the coming years we expect to be able to treat seriously ill CRSwNP patients that now need repetitive surgery and often also have severe asthma with these new monoclonal antibodies. At this moment the price of these new options is a major issue but we may hope and expect that finding the appropriate group of patients that benefit mostly from the treatment via precision medication will make the treatment available for all patients that need it. A totally new area of prediction of treatment effects lay ahead of us with new opportunities for our patients.

Loss of smell is an important and difficult to treat complaint of patients with CRS especially in patients with CRSwNP $(1,13,14)$ and it is important to realize that olfactory cleft opacification at the CT scan can predict improvement after ESS in CRSwNP (15). Olfaction is probably the most underestimated sense and olfactory loss is prevalent, and may induce significant mood disorders ${ }^{(16)}$. Fortunately smell disorders can be (partially) trained with smell training ${ }^{(17-19)}$ and maybe also other possibilities arise like application of intranasal insulin in patients with postinfectieus olfactory loss ${ }^{(20)}$. In this issue of the journal, Konstantinidis et al. for the first time show that one year olfactory training seems to be associated with better results in patients with post-infectious olfactory loss than a 16 week scheme ${ }^{(21)}$. An important finding for our daily practice.

\section{References}

1. Hopkins C, Philpott C, Crowe S, Regan S, Degun A, Papachristou I, et al. Identifying the most important outcomes for systematic reviews of interventions for rhinosinusitis in adults: working with Patients, Public and Practitioners. Rhinology. 2016;54(1):20-6.

2. Rudmik L, Soler ZM, Hopkins C, Schlosser RJ, Peters A, White AA, et al. Defining appropriateness criteria for endoscopic sinus surgery during management of uncomplicated adult chronic rhinosinusitis: a RAND/
UCLA appropriateness study. Rhinology. 2016;54(2):117-128.

3. Hopkins C, Andrews P, Holy CE. Does time to endoscopic sinus surgery impact outcomes in chronic rhinosinusitis? Retrospective analysis using the UK clinical practice research data. Rhinology. 2015;53(1):18-24.

4. Hopkins C, Rimmer J, Lund VJ. Does time to endoscopic sinus surgery impact outcomes in Chronic Rhinosinusitis? Prospective findings from the National Comparative Audit of Surgery for Nasal Polyposis and Chronic Rhinosinusitis. Rhinology. 2015;53(1):10-7.

5. Rudmik L, Soler ZM, Hopkins C. Using postoperative SNOT-22 to help predict the probability of revision sinus surgery. Rhinology. 2016;54(2):111-116.

6. Pundir V, Pundir J, Lancaster G, Baer S Kirkland $P$, Cornet $M$, et al. Role of corticosteroids in Functional Endoscopic Sinus Surgery--a systematic review and metaanalysis. Rhinology. 2016;54(1):3-19.

7. Fokkens WJ, Hellings PW. Rhinology in the 
forefront of European political attention. Rhinology. 2015;53(4):289.

8. Muraro A, Fokkens WJ, Pietikainen S, Borrelli D, Agache I, Bousquet J, et al. European symposium on precision medicine in allergy and airways diseases: report of the European Union parliament symposium (October 14, 2015). Rhinology. 2015;53(4):303-7.

9. Tomassen P, Vandeplas G, Van Zele T, Cardell LO, Arebro J, Olze H, et al. Inflammatory endotypes of chronic rhinosinusitis based on cluster analysis of biomarkers. J Allergy Clin Immunol. 2016 Mar 3. pii: S00916749(16)00184-6.

10. Bachert C, Mannent L, Naclerio RM, Mullol J, Ferguson BJ, Gevaert P, et al. Effect of Subcutaneous Dupilumab on Nasal Polyp Burden in Patients With Chronic Sinusitis and Nasal Polyposis: A Randomized Clinical Trial. JAMA. 2016;315(5):469-79.

11. Gevaert P, Calus L, Van Zele T, Blomme K, De Ruyck N, Bauters W, et al. Omalizumab is effective in allergic and nonallergic patients with nasal polyps and asthma. J Allergy Clin Immunol. 2013;131(1):110-6 e1.

12. Gevaert P, Van Bruaene N, Cattaert T,
Van Steen K, Van Zele T, Acke F, et al. Mepolizumab, a humanized anti-IL-5 $\mathrm{mAb}$, as a treatment option for severe nasal polyposis. J Allergy Clin Immunol. 2011;128(5):989-95 e1-8.

13. Dietz de Loos DA, Hopkins C, Fokkens WJ Symptoms in chronic rhinosinusitis with and without nasal polyps. Laryngoscope. 2013;123(1):57-63.

14. Fokkens WJ, Lund VJ, Mullol J, Bachert C, Alobid I, Baroody F, et al. EPOS 2012 European position paper on rhinosinusitis and nasal polyps 2012. Rhinol Suppl. 2012 Mar;(23): 1-298.

15. Vandenhende-Szymanski C, Hochet B, Chevalier D, Mortuaire G. Olfactory cleft opacity and CT score are predictive factors of smell recovery after surgery in nasal polyposis. Rhinology. 2015;53(1):29-34

16. Ahn S, Shin HW, Mahmood U, Khalmuratova $R$, Jeon SY, Jin HR, et al. Chronic anosmia induces depressive behavior and reduced anxiety via dysregulation of glucocorticoid receptor and corticotropin-releasing hormone in a mouse model. Rhinology. 2016;54(1):80-87.

17. Pekala K, Chandra RK, Turner JH. Efficacy of olfactory training in patients with olfactory loss: a systematic review and meta-analysis. Int Forum Allergy Rhinol. 2016 Mar;6(3):299307.

18. Welge-Lussen A, Looser GL, Westermann B, Hummel T. Olfactory source localization in the open field using one or both nostrils. Rhinology. 2014;52(1):41-7.

19. Mori E, Petters W, Schriever VA, Valder C, Hummel T. Exposure to odours improves olfactory function in healthy children. Rhinology. 2015;53(3):221-6.

20. Scho Pf V, Kollndorfer K, Pollak M, Mueller $C A$, Freiherr J. Intranasal insulin influences the olfactory performance of patients with smell loss, dependent on the body mass index: A pilot study. Rhinology. 2015;53(4):371-8.

21. Konstantinidis I, Tsakiropoulou E, Constantinidis J. Long term effects of olfactory training in patients with post-infectious olfactory loss. Rhinology. 2016.;54(2):170175.

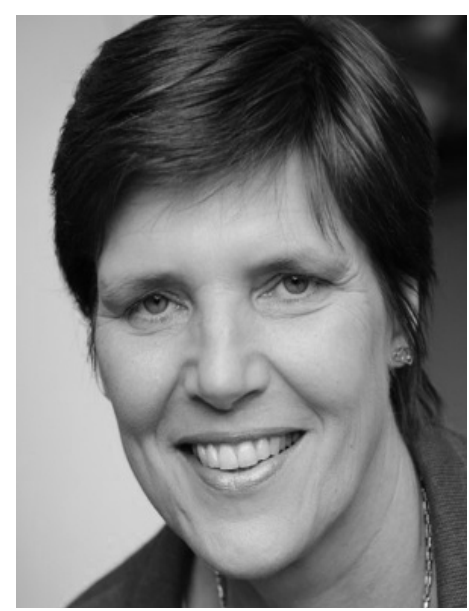

